\title{
BMJ Open Protocol of the SOMNIA project: an observational study to create a neurophysiological database for advanced clinical sleep monitoring
}

\author{
Merel M van Gilst (D , ,,2 Johannes P van Dijk, ${ }^{1,2}$ Roy Krijn, ${ }^{1,2}$ Bertram Hoondert, ${ }^{1,2}$ \\ Pedro Fonseca (D) , ${ }^{1,3}$ Ruud J G van Sloun, ${ }^{1}$ Bruno Arsenali, ${ }^{1}$ \\ Nele Vandenbussche, ${ }^{1,2}$ Sigrid Pillen, ${ }^{2,4}$ Henning Maass, ${ }^{3}$ Leonie van den Heuvel, ${ }^{3}$ \\ Reinder Haakma, ${ }^{3}$ Tim R Leufkens, ${ }^{3,4}$ Coen Lauwerijssen, ${ }^{5}$ Jan W M Bergmans, ${ }^{1,3}$ \\ Dirk Pevernagie, ${ }^{2}$ Sebastiaan Overeem (1) ${ }^{1,2}$
}

To cite: van Gilst MM, van Dijk JP, Krijn R, et al. Protocol of the SOMNIA project: an observational study to create a neurophysiological database for advanced clinical sleep monitoring. BMJ Open 2019;9:e030996. doi:10.1136/ bmjopen-2019-030996

- Prepublication history for this paper is available online. To view these files, please visit the journal online (http://dx.doi org/10.1136/bmjopen-2019030996).

Received 10 April 2019

Revised 22 0ctober 2019 Accepted 25 October 2019
Check for updates

(C) Author(s) (or their employer(s)) 2019. Re-use permitted under CC BY-NC. No commercial re-use. See rights and permissions. Published by BMJ.

For numbered affiliations see end of article.

Correspondence to

Dr Merel M van Gilst;

m.m.v.gilst@tue.nl

\section{ABSTRACT}

Introduction Polysomnography (PSG) is the primary tool for sleep monitoring and the diagnosis of sleep disorders. Recent advances in signal analysis make it possible to reveal more information from this rich data source. Furthermore, many innovative sleep monitoring techniques are being developed that are less obtrusive, easier to use over long time periods and in the home situation. Here, we describe the methods of the Sleep and Obstructive Sleep Apnoea Monitoring with Non-Invasive Applications (SOMNIA) project, yielding a database combining clinical PSG with advanced unobtrusive sleep monitoring modalities in a large cohort of patients with various sleep disorders. The SOMNIA database will facilitate the validation and assessment of the diagnostic value of the new techniques, as well as the development of additional indices and biomarkers derived from new and/or traditional sleep monitoring methods.

Methods and analysis We aim to include at least 2100 subjects (both adults and children) with a variety of sleep disorders who undergo a PSG as part of standard clinical care in a dedicated sleep centre. Full-video PSG will be performed according to the standards of the American Academy of Sleep Medicine. Each recording will be supplemented with one or more new monitoring systems, including wrist-worn photoplethysmography and actigraphy, pressure sensing mattresses, multimicrophone recording of respiratory sounds including snoring, suprasternal pressure monitoring and multielectrode electromyography of the diaphragm.

Ethics and dissemination The study was reviewed by the medical ethical committee of the Maxima Medical Center (Eindhoven, the Netherlands, File no: N16.074). All subjects provide informed consent before participation. The SOMNIA database is built to facilitate future research in sleep medicine. Data from the completed SOMNIA database will be made available for collaboration with researchers outside the institute.

\section{Strengths and limitations of this study}

- The Sleep and Obstructive Sleep Apnoea Monitoring with Non-Invasive Applications database will contain the gold standard in clinical sleep monitoring combined with several new techniques to monitor sleep and sleep-related phenomena.

- We create a large dataset including both adults and children, covering the whole spectrum of sleep disorders.

- The focus of this database is on diverse (sleep) pathologies and comorbidities, derived from a 'realworld' clinical setting.

- The size and variety of the dataset will make it a valuable source for a broad range of studies on sleep monitoring and diagnostics.

- The data will be available for collaboration on research in sleep medicine.

\section{INTRODUCTION}

Although we spend about one-third of our lives sleeping, sleep is still one of the most mysterious human behaviours. Because of the unconscious nature of sleep, studying this behaviour depends heavily on technology. Since the discovery of the human electroencephalography (EEG) in $1929,{ }^{1}$ this technique has been used to characterise the sleeping brain. In the mid-1930s, different sleep stages were first described ${ }^{2}$ and only in 1953 rapid eye movement (REM) sleep was formally described. ${ }^{3}$ In modern sleep medicine, EEG is still the most important component of polysomnography (PSG). ${ }^{4}$ With PSG, data about sleep stages and various physiological measures, such as respiration, heart rate, leg movements and body position are acquired and analysed simultaneously to 
gain insight into sleep patterns and the presence of sleep disorders.

With the large number of PSG sensors, sleep registrations contain a wealth of information. However, currently, this source is not used to its full potential. Although automatic analyses are available, in clinical practice PSG is still typically scored manually by a skilled technician. ${ }^{5}$ With the recent advances in signal analyses and machine learning, we are now capable of capturing even more complex information/patterns from the PSG $^{6}$ New parameters for diagnosis, symptom severity or clinical outcome might be found this way. Moreover, automatic detection of pathological phenomena is improving, such as sleep-related breathing events, ${ }^{78}$ movements related to movement disorders ${ }^{9}$ or nocturnal behaviour indicative of parasomnia ${ }^{10}$ is improving. Both traditional PSG sensors and new devices can be used for this purpose. Large, well-characterised datasets containing divergent sleep pathologies are now needed to develop and validate these kinds of algorithms. ${ }^{11}$

Because of the complex setup, PSG has limitations. Subjects have to sleep with many sensors attached to their head and body, often in an unfamiliar hospital environment. This may cause stress or anxiety and influence the findings (first night effect). ${ }^{12}$ Many sleep disorders show night-to-night variation, so clinical events can easily be missed with only one night of observation. These drawbacks are even more pronounced for the registration of sleep and sleep disorders in special populations, such as children, elderly and intellectually disabled subjects. These patients are easily intimidated by the large number of sensors and due to sensitive skin the use of contact sensors can be problematic. Furthermore, (visual) sleep scoring in these groups is more difficult and requires specific training. ${ }^{13}$

PSG remains the gold standard in sleep monitoring and diagnosis of sleep disorders, but many alternative techniques are being developed. These include a wide range of sensing modalities including wearable sensors and sensor mattresses. ${ }^{14}$ These advanced techniques have in common that they are non-invasive and minimally obtrusive, and therefore better accepted by patients. Furthermore, they are easy to use over longer periods of time and applicable in the home situation. Possibly these innovative solutions can play a role in treatment monitoring and the diagnosis of sleep disorders or eventually even substitute PSG in selected cases.

Application of sleep monitoring devices can roughly be divided into two categories: sleep staging and clinical event detection. Sleep stages are by definition based on EEG characteristics. ${ }^{4}$ However, surrogate measures based on movement or cardiorespiratory parameters are explored as well. Actigraphy is already a widely used measure for sleep/wake classification. ${ }^{15}$ The main application is to gain insight in rest-activity patterns over longer periods of time, for example, in case of (suspected) circadian rhythm disorders. ${ }^{4}$ Actigraphy has reasonable validity and reliability in healthy individuals with relatively good sleep patterns. However, the validity in special populations or in individuals with poor sleep or other sleep-related disorders is more questionable. ${ }^{16}$

Recently, sleep staging algorithms based on cardiac and respiratory signals have shown promising results in healthy subjects. ${ }^{17}$ They are based on sleep-stage specific patterns in heart rate variability (HRV) and respiration. ${ }^{18}$ These features can be derived from the ECG and respiration belts, but also from photoplethysmography (PPG) signals, which can be incorporated in wearable devices. ${ }^{19}$ Validation for this type of algorithms in patients is limited and has proven to be more challenging. ${ }^{20-22}$

Here, we describe the aims and methods of the Sleep and Obstructive Sleep Apnoea (OSA) Monitoring with Non-Invasive Applications (SOMNIA) project, which will yield a database containing clinical PSG combined with different advanced non-invasive sleep monitoring techniques in a large cohort of both adults and children with various sleep disorders from a tertiary referral sleep centre. Gold standard PSG will be augmented with a number of promising non-invasive monitoring systems, including wrist-worn PPG and actigraphy, pressure sensing mattresses, high fidelity acoustic recordings, suprasternal pressure monitoring and multielectrode electromyography of the diaphragm. The additional technologies are chosen based on their unobtrusiveness, broad range of sensing approaches, potential clinical value and previous proof of concept and validation studies. ${ }^{19} 2324$

An important focus of the SOMNIA database is on monitoring techniques for OSA, because this disorder is highly prevalent $\mathrm{t}^{25}$ and has serious (potential) health consequences. ${ }^{26}{ }^{27}$ Furthermore, in the current PSG montage, monitoring respiration requires the most obtrusive sensors. ${ }^{4}$ However, the database will also include insomnia, central disorders of hypersomnolence, circadian rhythm sleep-wake disorders, parasomnias, sleep-related movement disorders and cover as such the complete spectrum of sleep disorders, including complex and combined pathology.

The SOMNIA dataset can be used in several ways. First, it will allow validation of new sleep monitoring techniques in a representative group of sleep clinic patients. Second, the diagnostic value of these different techniques can be assessed, as well as additional indices that can be derived by combining different new and/or traditional PSG techniques. Finally, the data can be used to study the physiology of sleep (disorders) in a cohort of patients including complex pathology and comorbidities. The SOMNIA database will be made available as a 'neurophysiological biobank', to enable multidisciplinary collaborations to improve sleep diagnostics.

\section{METHODS AND ANALYSIS}

\section{Population}

The SOMNIA database will be created within Sleep Medicine Center Kempenhaeghe (Heeze, the Netherlands), a third-line expert centre for multidisciplinary sleep 
medicine. Subjects are recruited among patients who are planned for a PSG as part of the standard diagnostic process. We aim to include 2000 adults and 100 children with a variety of sleep disorders. We will include a minimum of 100 adults and 10 children per International Classification of Sleep Disorders (ICSD) diagnostic category: insomnia, sleep-related breathing disorders, central disorders of hypersomnolence, parasomnias and sleeprelated movement disorders. For the diagnosis of ICSD category circadian rhythm sleep-wake disorders, usually no clinical PSG is made, so we do not expect to include these patients as a separate group.

No formal exclusion criteria apply for this study. The overall goal of the study is to collect data of a representative sample of a patient population in a dedicated sleep centre, so the dataset will include patients from the complete spectrum of (complex) sleep disorders. However, patients with very complex sleep pathology or particularly severe comorbidity will most likely not be included, because these patients have higher clinical demands and data may be too difficult to interpret and less useful in groupwise comparison studies. The decision whether or not to ask a patient for inclusion in the study will be made by the treating physician.

Typical numbers of clinical PSGs made per ICSD disorder category, per year for the recruiting centre are: 400 insomnia, 850 sleep-related breathing disorders, 60 central disorders of hypersomnolence, 100 parasomnias and 200 sleep-related movement disorders. With a practical estimate of 1:3 patients eligible for the study and willing to participate, we are planning 4 years for the study to run.

\section{Recruitment and general study procedure}

Eligible patients who are scheduled for a PSG as part of usual medical care receive information about the study aims, procedures and the various additional sleep monitoring techniques. Depending on the technical utilities in the individually designated PSG bedroom, experimental sleep monitoring systems are added to the standard PSG. When it is not possible to add all sensors, a relevant subset is chosen. Participation in the study may never lead to interference with the clinical PSG. Depending on the clinical question underlying the sleep assessment, patients will use their regular medication and/or Continuous Positive Airway Pressure (CPAP) device during the sleep recording. All medication and other therapies are registered in the database.

\section{Polysomnography}

PSG registrations are made for one night. Patients stay at the inpatient clinic in an individual, sound-proof bedroom, under supervision of a sleep technologist.

Sleep is polysomnographically monitored using a dedicated recording system (Grael PSG, Compumedics, USA). For technical details, see table 1 . The primary sleep registration is based on the guidelines of the American Academy of Sleep Medicine (AASM), ${ }^{4}$ and consists of 6-channel EEG, 2-channel electro-oculography and electromyography of the mentalis muscle. Polygraphy recordings include ECG, respiratory flow (nasal and oral thermistors), nasal pressure (nasal cannula), respiratory effort based on thoracoabdominal respiratory inductance plethysmography, oxygen saturation (transmissive finger PPG), snoring (piezoelectric tracheal microphone), body position (gravity-based electric sensor) and electromyogram (EMG) of tibialis anterior muscle. A time-synchronised video registration (infrared camera) is part of the standard recording. In selected cases based on a specific clinical question, additional measurements may be added; these include, for example: oesophageal pressure monitoring (eg, for suspected OSA while standard PSG was negative, or a clinical suspicion of both central and obstructive events), transcutaneous $\mathrm{CO}_{2}$ measurements (eg, for a clinical suspicion of nocturnal hypoventilation) and additional EMG montages (eg, for suspected REM sleep behaviour disorder, propriospinal myoclonus or bruxism).

\section{Sleep and event scoring}

Sleep and associated events are scored according to the AASM 2015 criteria $^{5}$ using ProFusion software (ProFusion PSG V.4.00 (build 423), Compumedics, Australia). Respiratory events, snoring and limb movements are automatically scored by the software and subsequently checked and corrected by a certified sleep technician. All other events (eg, behaviour related to parasomnias or epilepsy, etc.) and sleep stages are scored by the technician without automatic prescoring. When oesophageal pressure (PES) monitoring is used, PES events are scored manually. Full scoring of Respiratory Event Related Arousals is available when performed for diagnostic purposes on clinical grounds.

\section{Clinical data}

At intake, the clinician records primary clinical data including demographic information, current medication, comorbidities and the results of screening questionnaires (if applicable; Epworth Sleepiness Scale, ${ }^{28}$ Pittsburgh Sleep Quality Index,${ }^{29}$ Insomnia Severity Index,${ }^{30}$ Hospital Anxiety and Depression Scale, ${ }^{31}$ Checklist Individual Strength fatigue ${ }^{32}$ Paris Arousal Disorders Severity Scale $(\text { PADDS })^{33}$ ). A final primary diagnosis is entered after the diagnostic trajectory for sleep pathology is finished. The diagnoses are coded according to the ICSD-2 criteria $^{34}$ which can be recoded according to ICSD-3 criteria ${ }^{4}$ but contain some more subcategories especially in the insomnia category. Secondary sleep pathology and categories of comorbidities are also recorded.

\section{Experimental measurement modalities \\ Wrist-worn PPG and actigraphy}

This wrist-worn sensor is a CE-marked logging device combining reflective PPG and a three-axial accelerometer sensors (Philips Research, Eindhoven, the Netherlands). For technical details, see table 2. The logging device is mounted on the non-dominant wrist of the participant (same hand as the finger PPG sensor), with the sensor 
Table 1 Technical specifications of the polysomnography (PSG) sensors

\begin{tabular}{|c|c|c|c|c|c|c|}
\hline PSG measure & Sensor & Manufacturer & Placement & $\begin{array}{l}\text { Sampling } \\
\text { frequency }(\mathrm{Hz})\end{array}$ & $\begin{array}{l}\text { High-pass } \\
\text { filter }(\mathrm{Hz})\end{array}$ & $\begin{array}{l}\text { Low-pass } \\
\text { filter (Hz) }\end{array}$ \\
\hline EEG & $\begin{array}{l}\mathrm{Ag} / \mathrm{AgCl} \text { surface } \\
\text { electrode }\end{array}$ & $\begin{array}{l}\text { MFI B.V., the } \\
\text { Netherlands }\end{array}$ & $\begin{array}{l}\text { F4-M1, C4-M1, O2- } \\
\text { M1, F3-M2. C3-M2, } \\
\text { O1-M2 (according to } \\
\text { international 10-20 } \\
\text { system) }\end{array}$ & 256 & 0.3 & 70 \\
\hline EOG & $\begin{array}{l}\mathrm{Ag} / \mathrm{AgCl} \text { surface } \\
\text { electrode }\end{array}$ & $\begin{array}{l}\text { MFI B.V., the } \\
\text { Netherlands }\end{array}$ & $\begin{array}{l}\mathrm{E} 1-\mathrm{M} 2(\mathrm{E} 1: 1 \mathrm{~cm} \text { below } \\
\text { and } 1 \mathrm{~cm} \text { lateral to the } \\
\text { left outer canthus), E2- } \\
\mathrm{M} 2 \text { (E2: } 1 \mathrm{~cm} \text { above } \\
\text { and } 1 \mathrm{~cm} \text { lateral to the } \\
\text { right outer canthus) }\end{array}$ & 256 & 0.3 & 70 \\
\hline EMG chin & $\begin{array}{l}\mathrm{Ag} / \mathrm{AgCl} \text { surface } \\
\text { electrode }\end{array}$ & $\begin{array}{l}\text { MFI B.V., the } \\
\text { Netherlands }\end{array}$ & $\begin{array}{l}\text { Chin } 1: 2 \mathrm{~cm} \text { below } \\
\text { inferior edge of the } \\
\text { mandible and } 2 \mathrm{~cm} \text { to } \\
\text { the left of the midline } \\
\text { Chin } 2: 2 \mathrm{~cm} \text { below } \\
\text { inferior edge of the } \\
\text { mandible and } 2 \mathrm{~cm} \text { to } \\
\text { the right of the midline } \\
\text { Chin } 3: \text { On the midline } \\
1 \mathrm{~cm} \text { above inferior } \\
\text { edge of the mandible }\end{array}$ & 512 & 15 & 150 \\
\hline ECG & $\begin{array}{l}\text { Electrode H34SG, } \\
\text { ECG +EEGEL } \\
46 \mathrm{~mm}\end{array}$ & Kendall, Ireland & $\begin{array}{l}\text { Single modified } \\
\text { electrocardiograph } \\
\text { Lead II torso electrode } \\
\text { placement }\end{array}$ & 512 & 0.3 & 70 \\
\hline EMG tibialis & $\begin{array}{l}\text { Electrode H34SG, } \\
\text { ECG +EEGEL } \\
46 \mathrm{~mm}\end{array}$ & Kendall, Ireland & $\begin{array}{l}\text { Longitudinally on both } \\
\text { legs and symmetrically } \\
\text { in the middle of the } \\
\text { anterior tibialis muscle } \\
2-3 \mathrm{~cm} \text { apart }\end{array}$ & 512 & 10 & 100 \\
\hline
\end{tabular}

Airflow:

\begin{tabular}{|c|c|c|c|c|c|c|}
\hline $\begin{array}{l}\text { Oronasal thermal } \\
\text { airflow }\end{array}$ & $\begin{array}{l}\text { SKU thermocouple } \\
\text { airflow sensor }\end{array}$ & $\begin{array}{l}\text { Compumedics, } \\
\text { Australia }\end{array}$ & Infranasal & 128 & 0.1 & 15 \\
\hline $\begin{array}{l}\text { Nasal pressure } \\
\text { transducer }\end{array}$ & $\begin{array}{l}\text { Cannula } 4000 \mathrm{~F} \\
\text { tube length } 7 \text { in }\end{array}$ & Salterlabs, USA & Infranasal & 128 & 0.1 & 15 \\
\hline \multicolumn{7}{|l|}{ Respiratory effort: } \\
\hline $\begin{array}{l}\text { Respiratory inductive } \\
\text { plethysmography } \\
\text { (RIP) }\end{array}$ & $\begin{array}{l}\text { Dual thoracic } \\
\text { abdominal RIP } \\
\text { bands }\end{array}$ & $\begin{array}{l}\text { Compumedics, } \\
\text { Australia }\end{array}$ & $\begin{array}{l}\text { Mid thorax and mid } \\
\text { abdomen }\end{array}$ & 128 & 0.1 & 15 \\
\hline $\begin{array}{l}\text { Oesophageal } \\
\text { manometry }\end{array}$ & $\begin{array}{l}\text { Gaeltec CTO-1 } \\
\text { single sensor } \\
\text { catheter }\end{array}$ & Gaeltec, Ireland & $\begin{array}{l}\text { Intraoesophageal, tip of } \\
\text { pressure senor above } \\
\text { the diaphragm }\end{array}$ & 128 & DC & 15 \\
\hline
\end{tabular}

\section{Oxygen saturation:}

\begin{tabular}{|c|c|c|c|c|c|c|}
\hline $\begin{array}{l}\text { Transmissive PPG/ } \\
\text { pulse oximetry }\end{array}$ & $\begin{array}{l}\text { NONIN Purelight, } \\
\text { flex sensor } 8000 \mathrm{~J}\end{array}$ & $\begin{array}{l}\text { Compumedics, } \\
\text { Australia }\end{array}$ & $\begin{array}{l}\text { Ring finger of the non- } \\
\text { dominant hand }\end{array}$ & 16 & - & - \\
\hline \multicolumn{7}{|l|}{ Snoring: } \\
\hline $\begin{array}{l}\text { Condensor mic. } \\
\text { sensor }\end{array}$ & $\begin{array}{l}\text { Grael Tracheal } \\
\text { Microphone }\end{array}$ & $\begin{array}{l}\text { Compumedics, } \\
\text { Australia }\end{array}$ & $\begin{array}{l}2 \mathrm{~cm} \text { lateral to the } \\
\text { cricothyriod cartilage }\end{array}$ & 1024 & 10 & 100 \\
\hline \multicolumn{7}{|l|}{ Body position: } \\
\hline $\begin{array}{l}\text { Gravity-detecting } \\
\text { electric sensor }\end{array}$ & $\begin{array}{l}\text { Grael position } \\
\text { sensor }\end{array}$ & $\begin{array}{l}\text { Sleepsense, } \\
\text { USA }\end{array}$ & $\begin{array}{l}\text { Placed on the front of } \\
\text { the thoracic RIP belt }\end{array}$ & 16 & - & - \\
\hline
\end{tabular}


Table 1 Continued

\begin{tabular}{|c|c|c|c|c|c|c|}
\hline PSG measure & Sensor & Manufacturer & Placement & $\begin{array}{l}\text { Sampling } \\
\text { frequency }(\mathrm{Hz})\end{array}$ & $\begin{array}{l}\text { High-pass } \\
\text { filter }(\mathrm{Hz})\end{array}$ & $\begin{array}{l}\text { Low-pass } \\
\text { filter (Hz) }\end{array}$ \\
\hline Transcutaneous $\mathrm{CO}_{2}$ & SDMS & Sentec, Swiss & $\begin{array}{l}\text { Earlobe (or forehead in } \\
\text { children) }\end{array}$ & 32 & - & - \\
\hline \multicolumn{7}{|l|}{ Infrared video: } \\
\hline Camera & $\begin{array}{l}\text { DinionHD } 1080 p \\
\text { IP-camera }\end{array}$ & Bosch, Germany & $\begin{array}{l}\text { At the ceiling above the } \\
\text { bed }\end{array}$ & - & - & - \\
\hline
\end{tabular}

EEG, electroencephalography; EMG, electromyogram; EOG, electro-oculogram; PPG, photoplethysmography; SDSM, SenTec Digital Monitoring System.

facing the skin on the dorsal side of the hand, above the ulnar styloid process (see figure 1).

The PPG logging device used in this project has been engineered to permit accurate PPG measurements, including the possibility to access data on beat-to-beat variability. Such measurements can be used to analyse HRV during the night, or to assess different cardiorespiratory parameters related to sleep. ${ }^{19}$ PPG algorithms have been developed to extract cardiac parameters such as average heart rate, HRV, as well as respiratory variables. ${ }^{19} 3536$
The clocks of the PPG sensor and the PSG are synchronised by compensating the clock offset and drift, based on an interpolated (at $4 \mathrm{~Hz}$ ) time series comprising the interbeat intervals detected from the PPG and another series from the interbeat intervals calculated from R-peaks detected from the ECG signal from the PSG. This guarantees that the recordings are perfectly aligned to the start time and that there is no clock drift between the two recorders. ${ }^{19}$

Table 2 Technical specifications of the experimental monitoring devices

\begin{tabular}{|c|c|c|c|c|}
\hline Device & Manufacturer & Placement & $\begin{array}{l}\text { Sampling } \\
\text { frequency }\end{array}$ & $\begin{array}{l}\text { Synchronisation to } \\
\text { PSG }\end{array}$ \\
\hline $\begin{array}{l}\text { Wrist-worn reflective } \\
\text { PPG and actigraphy }\end{array}$ & $\begin{array}{l}\text { Philips Research, } \\
\text { the Netherlands }\end{array}$ & $\begin{array}{l}\text { Non-dominant wrist, dorsal } \\
\text { side of the hand, above the } \\
\text { ulnar styloid process }\end{array}$ & $\begin{array}{l}\text { PPG: } 32 \mathrm{~Hz} \\
\text { Accelerometer: } \\
128 \mathrm{~Hz}\end{array}$ & $\begin{array}{l}\text { Cross correlation with } \\
\text { PSG recorded ECG/PPG } \\
\text { interbeat intervals }\end{array}$ \\
\hline Bed pressure sensor & $\begin{array}{l}\text { 2M Engineering, the } \\
\text { Netherlands }\end{array}$ & $\begin{array}{l}\text { Under the mattress: shoulder } \\
\text { region, abdominal region, hip } \\
\text { region (figure 1) }\end{array}$ & $100 \mathrm{~Hz}$ & $\begin{array}{l}\text { Sync pulse every } 10 \mathrm{~min} \\
\text { (via X-Link) }\end{array}$ \\
\hline \multicolumn{5}{|l|}{$\begin{array}{l}\text { Acoustic signal } \\
\text { registration: }\end{array}$} \\
\hline $\begin{array}{l}\text { M23 microphone (high } \\
\text { end) }\end{array}$ & Earthworks, USA & $\begin{array}{l}\text { Top end of the bed, midline } \\
\text { (figure } 2 \text { ) }\end{array}$ & $48 \mathrm{kHz}$ & $\begin{array}{l}\text { Continuous sync signal } \\
\text { (via X-Link) }\end{array}$ \\
\hline ECM8000 microphone & Behringer, Germany & $\begin{array}{l}\text { Top end of the bed, sides } \\
\text { (figure 2) }\end{array}$ & $48 \mathrm{kHz}$ & $\begin{array}{l}\text { Continuous sync signal } \\
\text { (via X-Link) }\end{array}$ \\
\hline \multicolumn{5}{|l|}{$\begin{array}{l}\text { Suprasternal pressure } \\
\text { monitoring }\end{array}$} \\
\hline Pressure sensor & $\begin{array}{l}\text { Sensym, } \\
\text { SDX010IND4 }\end{array}$ & $\begin{array}{l}\text { Over the trachea in the sternal } \\
\text { notch (figure 1) }\end{array}$ & $128 \mathrm{~Hz}$ & $\begin{array}{l}\text { NA (recorded with PSG } \\
\text { recorder) }\end{array}$ \\
\hline Tracheostomy fixation & $\begin{array}{l}\text { Provox Optiderm } \\
\text { Round } 7255\end{array}$ & & & \\
\hline Adapter & $\begin{array}{l}\text { 3D printed custom } \\
\text { device }\end{array}$ & & & \\
\hline
\end{tabular}

EEG, electroencephalography; PPG, photoplethysmography; PSG, polysomnography. 


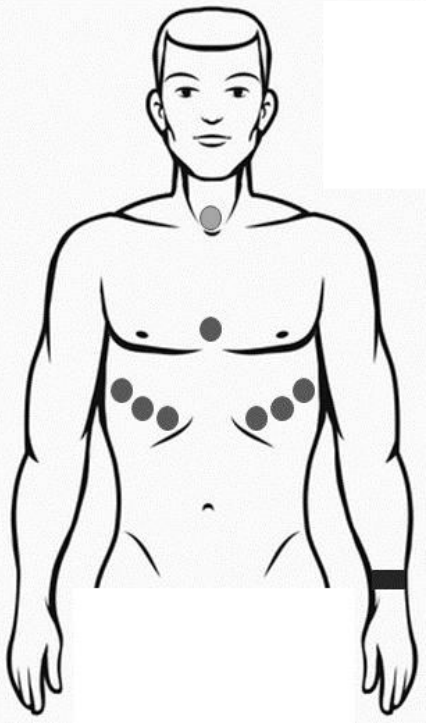

Figure 1 Placement of the body-worn experimental sensors. Light grey circle: suprasternal pressure monitoring; Dark gray circle: diaphragm EMG; Dark square: wrist-worn photoplethysmography. EMG, electromyogram.

\section{Bed pressure sensor}

The bed sensor system (2M Engineering, the Netherlands) is a set of highly sensitive, optical pressure sensors located between the bed base and the mattress. Three independent, contact-free sensors record pressure changes to a local storage device with a sample frequency of approximately $100 \mathrm{~Hz}$ (see table 2). Each sensor registers global pressure changes in one zone of the bed. They are located under the shoulder region, under the abdominal region and under the hip region. Large body movements like bed occupancy and turning will be extracted from the recorded pressure signal. ${ }^{24}$ Besides large pressure changes, the recorded signals also contain ballistic information about vital signs like breathing rate and heart rate. ${ }^{37} 38$

To postsynchronise the recorded data with the PSG data, a sync-pulse is stored locally but also sent from the bed sensor system to the PSG recording system every 10 min. The sync-pulse is recorded by the PSG system using an additional device for external signals (X-link, Compumedics USA), and synchronised with the PSG signals by the PSG software. Time synchronisation with the bed sensor is achieved by cross correlating these sync pulse signals.

\section{Audio recording for snoring analysis}

Nocturnal sounds are recorded using five non-contact omnidirectional condenser measurement microphones (see table 2); two for high-quality recordings (Earthworks M23) and three for average quality recordings (Behringer ECM8000). The microphones are placed at different heights at the top end of the bed, $60-120 \mathrm{~cm}$ from the head (see figure 2). Signals are recorded by a digital field recorder (Zoom F8) with a sampling frequency of $48 \mathrm{kHz}$ and a bit depth of 24 .

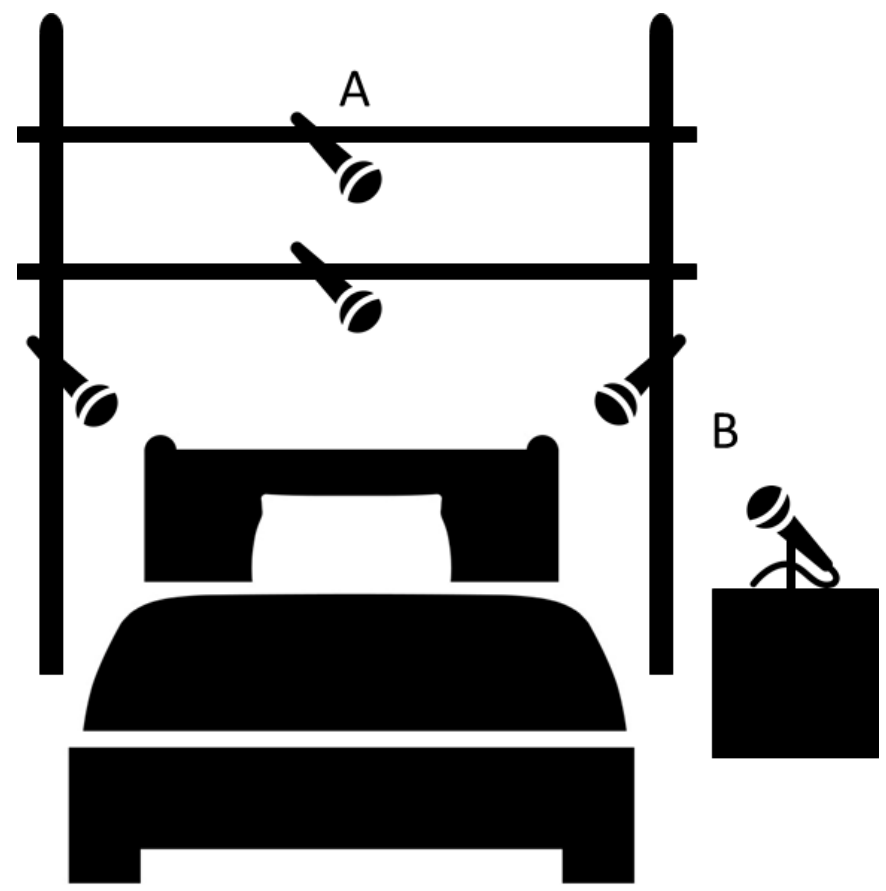

Figure 2 Microphone set-up at the top end of the bed. (A) Two microphones for high fidelity recordings (Earthworks M23) are placed at different heights at the midline of the bed. (B) Two microphones for average quality recordings (Behringer ECM8000) are placed at the same height at the sides of the bed and one on the night stand.

To synchronise the sound and PSG recordings, a modulated sinewave to yield a binary 'code' with a known time relation is generated using a USB development tool (C5505 eZdsp, Texas Instruments) and simultaneously fed to the audio recorder and PSG system using an additional device for external signals (X-link, Compumedics USA). The modulated sinewave is recorded synchronously with the PSG signals by the PSG software. These recordings are cross correlated for time synchronisation.

\section{Diaphragm electromyography}

Monitoring the electric activity of the diaphragmatic and intercostal muscular system is the most direct way to obtain information on respiratory muscle function. ${ }^{39}$ Eight unipolar surface electrodes are symmetrically placed in line in the sixth and seventh intercostal spaces; six on the frontal and two on the dorsal diaphragm. ${ }^{40}$ The reference electrode is placed on the sternum (see figure 1). The extra EMG signals are recorded using direct input channels of the PSG recorder (see table 2).

\section{Suprasternal pressure monitoring}

For suprasternal pressure monitoring, a microphone is embedded in a cuff and placed over the trachea in the sternal notch. ${ }^{41}$ This device is used as a pressure transducer. Provided that the cuff is adequately sealed to the skin to ensure an airtight cavity, changes in intrathoracic pressure can be converted into a legible signal of respiratory effort. ${ }^{23}$ 
Here, we use an in-house manufactured adaptation of the suprasternal pressure sensor based on a commercially available pressure sensor (Sensym, type: SDX010IND4), which is placed over the suprasternal notch and attached to the skin using a tracheostomy fixation adhesive (Provox Optiderm Round 7255). A custom-made 3D-printed adapter enables the pneumatic coupling to the pressure sensor. The signal is filtered and split into a respiratory signal and audio envelope. For respiration, the signal is limited by a low-pass $15 \mathrm{~Hz}$ filter while for removing cardiac artefacts an extra notch filter at $1.6 \mathrm{~Hz}$ is applied. For snoring, the signal is bandpass filtered between 30 and $450 \mathrm{~Hz}$ and rectified after which the envelope is determined and the signal is $\mathrm{dB}$ scaled. The suprasternal pressure signals are recorded using direct input channels of the PSG recorder at a sampling rate of $128 \mathrm{~Hz}$ (bandpass filter $\mathrm{DC}-35 \mathrm{~Hz}$ ). In addition, the original unfiltered suprasternal pressure signal is also recorded as an extra channel (sampling rate $1024 \mathrm{~Hz}$, bandpass filter DC-285 $\mathrm{Hz})$.

\section{Database}

When the diagnostic trajectory is finished and the patient has received a final diagnosis based on the PSG, all clinical and experimental data are combined. All data are converted to BioSemi Data Format, ${ }^{42}$ a 24-bit version of the 16-bit European Data Format 'plus' (EDF+). Sensor data are synchronised to the PSG and the data are transferred to the research database. Datasets that are exported for scientific research are pseudonymised using a study specific, unique coding, so different SOMNIA datasets cannot be related without the key file which is kept at Kempenhaeghe.

\section{DISCUSSION}

\section{SOMNIA opportunities}

Here, we describe the aims and methods of the SOMNIA project, to create a large-scale database containing standardised PSG data and data from new, unobtrusive technologies to measure sleep (related) phenomena, in a real-world clinical setting. The current framework facilitates the validation of such new techniques and allows the diagnostic value of these techniques to be assessed, as well as the development of additional indices and biomarkers that can be derived by combining different new and/or traditional sleep monitoring methods. The large number of patients and wide variety of sleep disorders will make the SOMNIA database a valuable source for a broad range of studies on sleep monitoring and diagnostics.

\section{Focus on diverse pathologies and comorbidities}

Currently, there are several sleep databases available. For example, the Wisconsin Sleep Cohort (WSC), ${ }^{43}$ the Sleep Heart Health study (SHHS) ${ }^{44}$ and the Siesta database. ${ }^{45}$ Both the WSC $(n=1500)$ and SHHS $(n=6600)$ are large population-based studies with a special focus on sleepdisordered breathing. The Siesta database is smaller and contains PSGs of 194 healthy subjects and 98 patients. The advantage of the SOMNIA database over the existing studies is that it is completely focused on patient data and all primary sleep disorders will be represented.

The SOMNIA data are acquired in a tertiary care referral centre, where a wide variety of (rare) sleep disorders are diagnosed and treated. By integrating research into regular care, it is possible to include a large number of patients with various sleep disorders. All experimental techniques are non-invasive and non-minimally or minimally obtrusive. The study requires no extra visits for the patient outside their regular care. Consequently, this study comprises no extra burden for the patient and almost all patients are eligible for participation. Also complex patients with multiple sleep disorders or comorbidities such as Parkinson's disease, psychiatric or cardiovascular disorders will be included. For specific (combinations of) rare sleep disorders, it might be challenging to include large sample sizes in SOMNIA. However, it is important to have data from these patients available for validation studies aiming towards the general sleep clinic population. This allows validation of new techniques in a 'realworld' clinical setting with its inherent variability and complexity. Furthermore, it provides the opportunity to study the influence of comorbid (sleep) disorders. For example, comorbid insomnia and OSA are gaining attention. ${ }^{46} 47$ However, in datasets collected in population studies or second-line sleep clinics, there are limited data available on this comorbid condition. The SOMNIA database can be used to study the (patho) physiology of these complex patients in more detail.

\section{Unobtrusive sensing technologies}

Despite the technical revolution of the past decades, sleep medicine and sleep research still rely on relatively cumbersome diagnostic tools. For example, the diagnosis of OSA relies on several sensors to characterise the nature of sleep-disordered breathing. Measurements of respiration, nasal pressure, blood-oxygen saturation and respiratory effort are typical parts of the standard PSG montage. Respiration is the result of muscle activity that induces negative intrathoracic pressure and expansion of the thoracic and abdominal cavities. Therefore, respiratory effort may be recorded from mechanical, electrical and electromechanical signals. ${ }^{23}$ The revised manual for the scoring of sleep and associated events by the AASM recommends the use of oesophageal manometry or dual thoracoabdominal respiratory inductance plethysmography for this purpose. ${ }^{5}$ Especially, the first is an unpleasant procedure, which is often not very well tolerated by patients. ${ }^{48}$ Modern, less invasive sensing technologies such as wrist-worn reflective PPG, snoring analyses, diaphragm EMG and suprasternal pressure measurement all have the potential to capture respiratory characteristics of OSA specifically, and in general, physiological characteristics that might aid in the diagnosis, treatment and follow-up of sleep disorders. However, validation in a real-world clinical setting is 
limited and the usefulness of these sensors in clinical practice remains unproven. These aspects are important because devices and algorithms that are developed for healthy users are not readily applicable to patients with sleep disturbances. ${ }^{22}$

\section{Children}

Paediatric sleep medicine is a young field of research and not many large-scale studies are available. We will make a specific effort to also include a significant number of children in the SOMNIA database. There are essential differences between paediatric and adult patients. In children, other sleep disorders occur and sleep disorders can present themselves in a different way. For example, children do tend to have clinical symptoms of OSA with a much lower Apnoea Hypopnoea Index compared with adults. ${ }^{49}$ Moreover, obstructive events in children occur primarily during REM sleep.$^{50}$ If an insufficient amount of REM sleep is captured during a PSG, for example, due to sleep disruption because of the uncomfortable monitoring equipment, the degree of OSA is likely to be underestimated. So, for this challenging group of patients, it is even more important to develop sleep monitoring techniques that are less obtrusive and intimidating. Furthermore, age is not only a determining factor in how long people sleep, it also has large influence on PSG characteristics, which is reflected in dedicated scoring rules for children and adolescents. ${ }^{13}$ Algorithms developed for analysis of adult sleep should be tested and probably adapted for the paediatric population. Although the sample sizes for paediatric patients will be much smaller than for adults, results from the SOMNIA database could give an indication for the potential usefulness of new nonobtrusive technologies or of adapted analysis algorithms. These could then be further validated in dedicated future studies, including directed efforts to obtain reference data.

In conclusion, with the SOMNIA project, we are creating a neurological database for advanced sleep monitoring in a clinical setting. The data can be used for a broad spectrum of studies, ranging from innovative PSG analyses to the validation of experimental sleep monitoring devices.

\section{ETHICS AND DISSEMINATION}

\section{Ethics approval and consent to participate}

According to the Dutch directives on research in human subjects, the study was reviewed by the medical ethical committee of the Maxima Medical Center (Eindhoven, the Netherlands, File no: N16.074). The study protocol was approved by the internal review boards of both the Kempenhaeghe Sleep Center (Heeze, the Netherlands) and Philips Research (Eindhoven, the Netherlands).

All subjects provide informed consent before participation. For the children, the information is given to the child as well as the parents (or legal guardians). Informed consent by both parents (or legal guardians) and children (age $\geq 12$ years) is required in order to enter the study.

\section{Availability of data and materials}

The SOMNIA database is built to facilitate future research in sleep medicine. Data from the completed SOMNIA database will be made available for collaboration with researchers outside the institute. To get access to the data, a researcher must submit a research protocol, with a clear scientific question, to the Kempenhaeghe Center for Sleep Medicine. An internal review board will review the data request. When the study fits the vision of the SOMNIA project, the researcher will receive a pseudonymised copy of the requested data, to be used in that specific study. Specific restrictions apply to the availability of the data from the wrist-worn PPG sensor (Philips) and optical pressure sensor (2M Engineering), which are used under license and are not publicly available. These data are however available from the authors on reasonable request and with permission of Philips or $2 \mathrm{M}$ Engineering.

When the study is finished, the researcher returns the data. Kempenhaeghe will store the original dataset for at least 15 years.

\section{Author affiliations}

${ }^{1}$ Electrical Engineering, Technische Universiteit Eindhoven, Eindhoven, The Netherlands

${ }^{2}$ Center for Sleep Medicine, Kempenhaeghe Foundation, Heeze, Noord Brabant, The Netherlands

${ }^{3}$ Philips Research, Eindhoven, North Brabant, The Netherlands

${ }^{4}$ Industrial Design, Technische Universiteit Eindhoven, Eindhoven, The Netherlands ${ }^{5} 2 \mathrm{M}$ Engineering, Valkenswaard, The Netherlands

Acknowledgements The authors would like to thank all somnologists, sleep technicians and nurses at the Center for Sleep Medicine Kempenhaeghe for making this study possible. The SOMNIA study runs within the Eindhoven Medtech Innovation Center.

Contributors MMvG designed the study, arranged the data collection and drafted the manuscript. JPvD was involved in the study design and in writing the manuscript. RK designed the database. BH managed the data collection. PF, RJGvS, BA, NV, TL, CL, HM, RH, JWMB and LvdH assisted with implementing the experimental technologies. NV, SP and DP provided clinical expertise for the study design. S0 conceived and supervised the study, was involved in the study design and in writing the manuscript. All authors read and approved the final manuscript.

Funding Parts of this study were supported by an Impulse grant (Advanced Sleep Monitoring, 2016), Open technology program (OSA+, STW/NWO, project no. 14619) and OPZuid (Bedsense, 2015).

Disclaimer These funding sources had no role in either study design or writing of the manuscript.

Competing interests PF, TL, HM, RH, JWMB and LvdH are employees of Philips Research. $\mathrm{CL}$ is employee of $2 \mathrm{M}$ Engineering.

Patient consent for publication Not required.

Ethics approval Maxima Medical Center (Eindhoven, the Netherlands, File no: N16.074).

Provenance and peer review Not commissioned; externally peer reviewed.

Open access This is an open access article distributed in accordance with the Creative Commons Attribution Non Commercial (CC BY-NC 4.0) license, which permits others to distribute, remix, adapt, build upon this work non-commercially, and license their derivative works on different terms, provided the original work is properly cited, appropriate credit is given, any changes made indicated, and the use is non-commercial. See: http://creativecommons.org/licenses/by-nc/4.0/.

\section{ORCID iDs}

Merel M van Gilst http://orcid.org/0000-0003-2138-5686

Pedro Fonseca http://orcid.org/0000-0003-2932-6402

Sebastiaan Overeem http://orcid.org/0000-0002-6445-9836 


\section{REFERENCES}

1 Berger H. Über das Elektrenkephalogramm des Menschen. Archiv für Psychiatrie und Nervenkrankheiten 1929;87:527-70.

2 Loomis AL, Harvey EN, Hobart G. Further observations on the potential rhythms of the cerebral cortex during sleep. Science 1935;82:198-200.

3 Aserinsky E, Kleitman N. Regularly occurring periods of eye motility, and concomitant phenomena, during sleep. Science 1953;118:273-4.

4 American Academy of Sleep Medicine. International classification of sleep disorders. 3rd edn, 2014.

5 Berry R, Brooks R, Gamaldo C. The AASM manual for the scoring of sleep and associated events: rules, terminology and technical specifications version 2. 2nd edn. Darien, Illinois: American Academy of Sleep Medicine, 2015.

6 Pombo N, Garcia N, Bousson K. Classification techniques on computerized systems to predict and/or to detect apnea: a systematic review. Comput Methods Programs Biomed 2017;140:265-74.

7 Varon C, Caicedo A, Testelmans D, et al. A novel algorithm for the automatic detection of sleep apnea from Single-Lead ECG. IEEE Trans Biomed Eng 2015;62:2269-78.

8 Babaeizadeh S, White DP, Pittman SD, et al. Automatic detection and quantification of sleep apnea using heart rate variability. J Electrocardiol 2010;43:535-41.

9 Wetter TC, Dirlich G, Streit J, et al. An automatic method for scoring leg movements in polygraphic sleep recordings and its validity in comparison to visual scoring. Sleep 2004;27:324-8.

10 Kempfner J, Jennum P, Nikolic M, et al. Automatic detection of REM sleep in subjects without atonia. Conf Proc IEEE Eng Med Biol Soc 2012;2012:4242-5

11 Bragazzi NL, Guglielmi O, Garbarino andS. SleepOMICS: how big data can revolutionize sleep science. Int J Environ Res Public Health 2019;16:291.

12 Newell J, Mairesse O, Verbanck P, et al. Is a one-night stay in the lab really enough to conclude? First-night effect and night-to-night variability in polysomnographic recordings among different clinical population samples. Psychiatry Res 2012;200:795-801.

13 Grigg-Damberger M, Gozal D, Marcus CL, et al. The visual scoring of sleep and arousal in infants and children. J Clin Sleep Med 2007;3:201-40.

14 Van de Water ATM, Holmes A, Hurley DA. Objective measurements of sleep for non-laboratory settings as alternatives to polysomnography--a systematic review. J Sleep Res 2011;20:183-200.

15 Ancoli-Israel S, Cole R, Alessi C, et al. The role of actigraphy in the study of sleep and circadian rhythms. Sleep 2003;26:342-92.

16 Sadeh $A$. The role and validity of actigraphy in sleep medicine: an update. Sleep Med Rev 2011;15:259-67.

17 Willemen T, Van Deun D, Verhaert V, et al. An evaluation of cardiorespiratory and movement features with respect to sleep-stage classification. IEEE J Biomed Health Inform 2014;18:661-9.

18 Fonseca P, Long X, Radha M, et al. Sleep stage classification with ECG and respiratory effort. Physiol Meas 2015;36:2027-40.

19 Fonseca P, Weysen T, Goelema MS, et al. Validation of Photoplethysmography-Based sleep staging compared with polysomnography in healthy middle-aged adults. Sleep 201710.1093/sleep/zsx097. [Epub ahead of print: 01 Jul 2017].

20 Willemen T, Varon C, Dorado AC, et al. Probabilistic cardiac and respiratory based classification of sleep and apneic events in subjects with sleep apnea. Physiol Meas 2015;36:2103-18.

21 Redmond SJ, Heneghan C. Cardiorespiratory-based sleep staging in subjects with obstructive sleep apnea. IEEE Trans Biomed Eng 2006;53:485-96.

22 Fonseca $\mathrm{P}$, den Teuling $\mathrm{N}$, Long $\mathrm{X}$, et al. A comparison of probabilistic classifiers for sleep stage classification. Physiol Meas 2018;39:055001.

23 Vandenbussche NL, Overeem S, van Dijk JP, et al. Assessment of respiratory effort during sleep: esophageal pressure versus noninvasive monitoring techniques. Sleep Med Rev 2015;24:28-36.

24 Walsh L, Moloney E, McLoone S. Identification of nocturnal movements during sleep using the non-contact under mattress bed sensor. Conf Proc IEEE Eng Med Biol Soc 2011;2011:1660-3.
25 Punjabi NM. The epidemiology of adult obstructive sleep apnea. Proc Am Thorac Soc 2008:5:136-43.

26 Parish JM, Somers VK. Obstructive sleep apnea and cardiovascular disease. Mayo Clin Proc 2004;79:1036-46.

27 Calvin AD, Albuquerque FN, Lopez-Jimenez F, et al. Obstructive sleep apnea, inflammation, and the metabolic syndrome. Metab Syndr Relat Disord 2009;7:271-7.

28 Johns MW. A new method for measuring daytime sleepiness: the Epworth Sleepiness scale. Sleep 1991;14:540-5.

29 Buysse DJ, Reynolds CF, Monk TH, et al. The Pittsburgh sleep quality index: a new instrument for psychiatric practice and research. Psychiatry Res 1989;28:193-213. 3rd.

30 Morin CM, Belleville G, Bélanger L, et al. The insomnia severity index: psychometric indicators to detect insomnia cases and evaluate treatment response. Sleep 2011;34:601-8.

31 Zigmond AS, Snaith RP. The hospital anxiety and depression scale. Acta Psychiatr Scand 1983;67:361-70.

32 Bültmann U, de Vries M, Beurskens AJ, et al. Measurement of prolonged fatigue in the working population: determination of a cutoff point for the checklist individual strength. J Occup Health Psychol 2000;5:411-6.

33 Arnulf I, Zhang B, Uguccioni G, et al. A scale for assessing the severity of arousal disorders. Sleep 2014;37:127-36.

34 American Academy of Sleep Medicine. International classification of sleep disorders. 2nd ed, 2005

35 Papini GB, Fonseca P, Aubert XL, et al. Photoplethysmography beat detection and pulse morphology quality assessment for signal reliability estimation. Conf Proc IEEE Eng Med Biol Soc 2017;2017:117-20.

36 Papini GB, Fonseca P, Eerikäinen LM, et al. Sinus or not: a new beat detection algorithm based on a pulse morphology quality index to extract normal sinus rhythm beats from wrist-worn photoplethysmography recordings. Physiol Meas 2018;39:115007.

37 Paalasmaa J, Waris M, Toivonen $\mathrm{H}$, et al. Unobtrusive online monitoring of sleep at home. Conf Proc IEEE Eng Med Biol Soc 2012;2012:3784-8

38 Tenhunen M, Elomaa E, Sistonen $\mathrm{H}$, et al. Emfit movement sensor in evaluating nocturnal breathing. Respir Physiol Neurobiol 2013;187:183-9.

39 Hirshkowitz M, MH K. Monitoring techniques for evaluating suspected sleep-disordered breathing. In: Kryger MH, Roth T, WC $\mathrm{D}$, eds. Principles and practice of sleep medicine. 5th edn. St. Louis, MO, USA: Elsevier Saunders, 2011: 1610-23.

40 Maarsingh EJ, van Eykern LA, Sprikkelman AB, et al. Respiratory muscle activity measured with a noninvasive EMG technique: technical aspects and reproducibility. J Appl Physiol 2000;88:1955-61.

41 Meslier N, Simon I, Kouatchet A, et al. Validation of a suprasternal pressure transducer for apnea classification during sleep. Sleep 2002;25:753-7.

42 Biosemi. Available: https://www.biosemi.com/faq/file_format.htm

43 Young T, Palta M, Dempsey J, et al. Burden of sleep apnea: rationale, design, and major findings of the Wisconsin sleep cohort study. WMJ 2009;108:246-9.

44 Quan SF, Howard BV, Iber C, et al. The sleep heart health study: design, rationale, and methods. Sleep 1997;20:1077-85

45 Klösch G, Kemp B, Penzel T, et al. The SIESTA project polygraphic and clinical database. IEEE Eng Med Biol Mag 2001;20:51-7.

46 Cho YW, Kim KT, Moon H-J, et al. Comorbid insomnia with obstructive sleep apnea: clinical characteristics and risk factors. J Clin Sleep Med 2018;14:409-17.

47 Luyster FS, Buysse DJ, Strollo PJ. Comorbid insomnia and obstructive sleep apnea: challenges for clinical practice and research. J Clin Sleep Med 2010;6:196-204.

48 Woodson BT, Wooten MR. A multisensor solid-state pressure manometer to identify the level of collapse in obstructive sleep apnea. Otolaryngol Head Neck Surg 1992;107:651-6.

49 Marcus CL. Sleep-disordered breathing in children. Curr Opin Pediatr 2000;12:208-12.

50 Goh DY, Galster P, Marcus CL. Sleep architecture and respiratory disturbances in children with obstructive sleep apnea. Am J Respir Crit Care Med 2000;162:682-6. 